\title{
Cancer Immunogene Therapy: Antisense and Triple Helix Aproach
}

\author{
Gabriela Quintero ${ }^{1}$, Carlos Rojas ${ }^{2}$, Juan J Rey ${ }^{1}$ and Jerzy Trojan*1 \\ ${ }^{1}$ Faculty of Health Sciences, UNAB University, Floridablanca, Colombia \\ ${ }^{2}$ Faculty of Health Sciences, UNAB University, and International Foscal Clinic, Floridablanca, Colombia
}

Received: March 20, 2018; Published: April 05, 2018

*Corresponding author: Jerzy Trojan, Faculty of Health Sciences, UNAB University, Floridablanca, Colombia and INSERM U602, Cancer Center, Paris Sud University, Villejuif, France, Tel: 57-3106947629; Email: genetherapy@hotmail.fr

\section{Introduction}

Cellular immunogene therapy inducing immune anti-tumor response constitutes one of the latest strategies for the treatment of many forms of cancers. From 2015, the cancer immunotherapy became an obligatory complement therapy in USA: The Cancer Moonshot Task program supervised by USA government and the cancer immunotherapy program established in Parker Institute in Los Angeles-the common program of the best university hospitals in USA [1]. The beginning of our Anti-gene (antisense and triple helix) IGF-I cellular immunogene Phase I trial in USA and Europe has presented promising results: an increase in immune response goes together with life span, and confirms the role of the immune phenomenon in the suppressing of animal tumors treated experimentally by the same cellular immunogene therapy. We need to underline, that our clinical trial was realized following the establishment of immunogene therapy as a clinical domain. This approach is based on suppression of growth factor IGF-I in cancers cells [2-5].

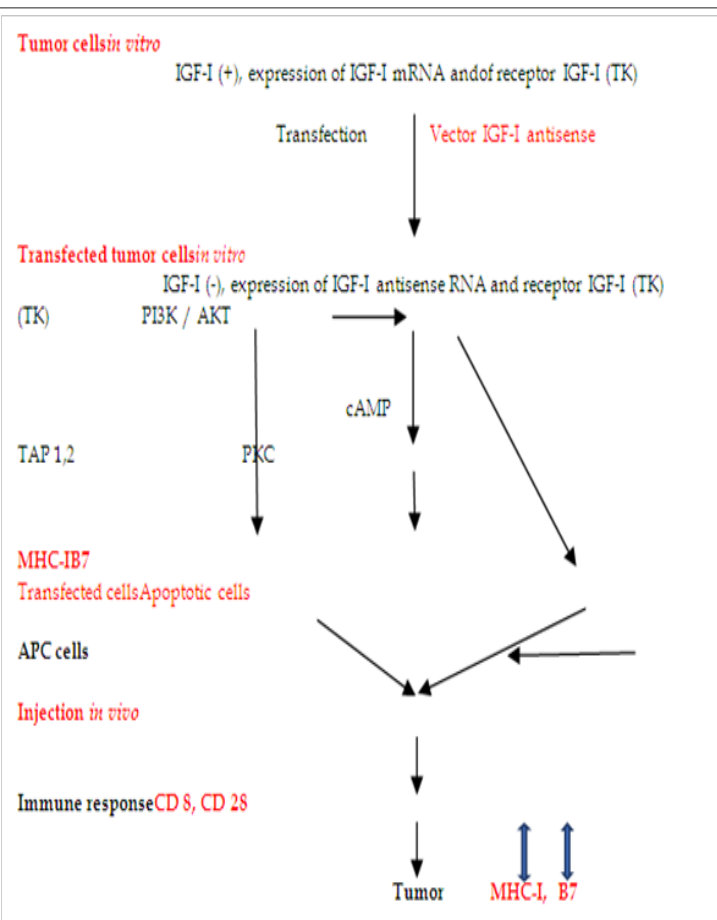

Figure 1: Mechanism of IGF-I antisense immunogene therapy. Cancer cells transfected with a vector encoding IGF-I cDNA in antisense orientation express MHC-I and B7 molecules. These immunogenic cells become also apoptotic. The APC - antigen presenting cells which are involved in tumor-immunogenicity mechanisms activate lymphocytes T CD8 and CD28. The last ones form the bridges with MHC-1 and B7 present in the solid tumor inducing anti-tumor processesafter everyofthreevaccinations $[7,12]$. 
Alteration in expression of growth factors is associated with growth and development of human tumors. One such growth factor is IGF-I, a 70-amino acid polypeptide. Using IGF-I as the diagnosis marker, 17 different tumors are known to express IGF-I gene. IGF I seems to play a major role in neuroectodermal tumors such as glioblastoma (the most frequent brain tumor in man and usually fatal), as in other tumors - mesodermal i.e. prostate adenocarcinoma, and endodermal i.e. colon adenocarcinoma [6,7]. In the preclinical experimental studies, C6 and CNS-1 rat glioma, or LFC rat hepatoma cells, and PCC3 murine teratocarcinoma cells transfected with a pAnti-IGF-I vector or with a pIGF-I TH vector (antisense or triple helix technology), became immunogenic expressing MHC-I and B7 antigens. Moreover, the transfected tumor cells became apoptotic. These cells injected into syngeneic animals induced a T-cell mediated immune reaction both against themselves and against their non transfected tumorigenic progenitor cells. IGF-I antisense or triple helix transfectants were shown to elicit a curative antitumor immune response with tumor regression at distal sites [8] (Figure 1). Our strategy of treatment of malignant tumors is based on:

\section{a) Diagnosis using IGF-I gene expression as differential marker}

b) Enhancement of tumor using antisense and triple helix anti - IGF-I technology. In this type of immunogene therapy, the tumor cells are down-regulated in production of IGF-I when transfected with vectors either expressing IGF-I antisense RNA or inducing IGF-I RNA-DNA triple helix. The transfected cells lose tumorigenicity and elicit tumor specific immunity which leads to the cure of established tumors [8].

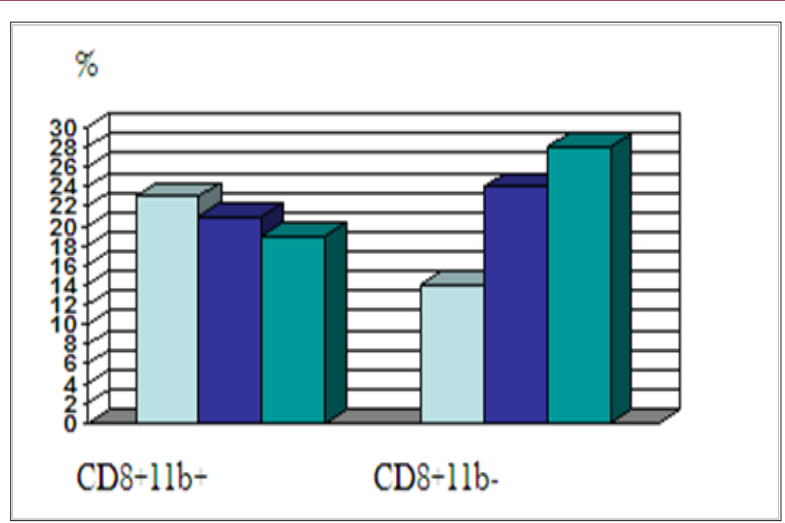

Figure 2: Increase of CD8+11b- in PBL cells removed from blood cells of treated glioblastoma patientsafter every of three successive vaccinations, once a month (cytofluorometry, Becton Dickinson) [12,13].

Both IGF-I anti-gene therapies: IGF-I antisense and IGF-I triple helix, were introduced in clinical trial of glioblastoma (Cleveland, USA; Bangkok, Thailand; Bromberg, Poland-collaboration with Paris, France), liverhepatocarcinoma (Shanghai, China, and Cracow, Poland), cancers of prostate, colon, liver, uterus and ovary (NATO Science Program-USA, France, Poland, Germany), and melanoma, prostate and colon (Bogota and Bucaramanga, Colombia - clinical study in progress) [5,7-11]. The first clinical results were very promising and indicated an increase in immune response in vaccinated patients. All patients showed phenotypic changes in PBL; in general, the specific features of activation, both Th and Tc populations were observed in our results, especially an increase in CD8+ percentage with characteristics switching from CD8+CD11b+ to CD8+CD11b- phenotype. The life span of treated glioblastoma patients ranged between 18 and 24 months and in some cases the observed survival was 3 and 4 years. Similar results of CD8 typing were observed in immunogene therapy of other tumors (i.e. prostate, colon and liver cancers) $[7,12]$ (Figure 2). In the first step of clinical trial Phase I proposed in Colombia in UNAB University/ Foscal Clinic, three to four cases of every following cancer diseases will be treated: glioblastoma, cancers of prostate and colon $[12,13]$.

\section{References}

1. https://www.cancer.gov/research/key-initiatives/moonshot-cancerinitiative/blue-ribbon panel/blue-ribbon-panel-report-2016.pdff

2. Weintraub H, Izant J, Harland R (1985) Antisense RNA as a molecular tool for genetianalysis. Trends in Genetics 1(1): 23-25.

3. Dervan PB (1992) Reagents for the site-specific cleavage of megabase DNA. Nature 359: 87-88.

4. Trojan J, Johnson T, Rudin S, Ilan Ju, Tykocinski M, et al. (1993) Treatment and prevention of rat glioblastoma by immugenic C6 cells expressing antisense insulin-like growth factor I RNA. Science 259(5091): 94-97.

5. (1990) Wikipedia-Encyclopedia. Gene Therapy, History.

6. Daughaday WH, Rotwein P (1989) Insulin-Like Growth Factors I and II. Peptide, messenger ribonucleic acid and gene structures, serum, and tissue concentrations. Endocrin Rev 10(1): 68-91.

7. Trojan J, Pan YX, Wei MX, LyA, Shevelev A, et al. (2012) Methodology for anti - gene anti - IGF-I therapy of malignant tumours. Chemother Res Pract p. 12.

8. Trojan A, Ly A, Wei MX, Pan YX, Kopinski P, et al. (2017) Experimental and clinical anti-gene anti IGF-I therapy. In J Trojan (Eds.). Cancer immunogene therapy. Anti - gene anti IGF-I approach. Case of glioblastoma. Lambert Academic Publishers, Germany 3: 68-91.

9. Wongkajornsilp A, Ouyprasertkul M, Sangruchi T, Huabprasert S, Pan YX, et al. (2001) The analysis of peri-tumor, necrosis following the subcutaneous implantation of autologous tumor cell transfected with an episome transcribing anantisense insulin-like growth factor 1 RNA in a glioblastoma multiforme subject. J Med Assoc Thai 84(3): 740-747.

10. Popiela T, Sierzega M, Gach T, Jarocki P, Trojan J (2003) Phase I trial of colorectal cancer immunotherapy using autologous cancer cells transfected with an IGF-I antisense plasmid. Acta Chirurg Belg 5(103): 2-3.

11. Zhu C, Trabado S, Fan Y, Trojan J, Lone YC, et al. (2015) Characterization of effector components from the humoral and cellular immune response stimulated by melanoma cells exhibiting modified IGF-1 expression. Biomed \& Pharmacother 70: 53-57.

12. Trojan J (2016) Anti-Gene anti IGF-I technology applied for cancer immunotherapy. World J Res Rev 1(3): 67-75.

13. Castillo T, Trojan A, Noguera MC, Jay ML, Crane C, et al. (2016) Epistemiologic experience in elaboration of molecular biology technology for immunogene therapy (in Spanish). Rev Cien 2 (25): 228240 . 


\section{(C) (i) This work is licensed under Creative}

Submission Link: https://biomedres.us/submit-manuscript.php

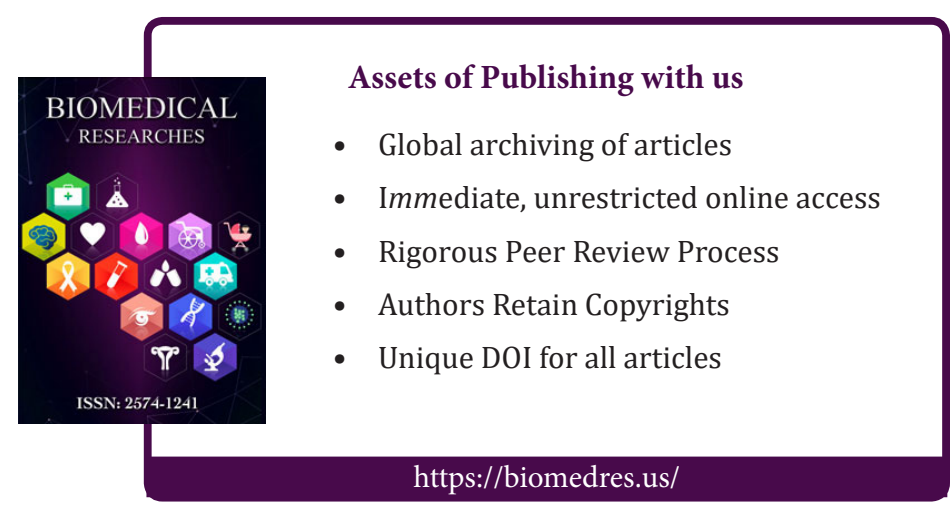

